\title{
Intraoperative oxygenation in adult patients undergoing surgery (iOPS): a retrospective observational study across 29 UK hospitals
}

Clare M. Morkane ${ }^{1 \dagger}$, Helen McKenna ${ }^{1 \dagger}$, Andrew F. Cumpstey ${ }^{2 \dagger}$, Alex H. Oldman ${ }^{3}$, Michael P. W. Grocott ${ }^{2}$, Daniel S. Martin ${ }^{1 *}$ and Pan London Perioperative Audit and Research Network (PLAN) South Coast Perioperative Audit and Research Collaboration (SPARC)

\begin{abstract}
Background: Considerable controversy remains about how much oxygen patients should receive during surgery. The 2016 World Health Organization (WHO) guidelines recommend that intubated patients receive a fractional inspired oxygen concentration $\left(\mathrm{FlO}_{2}\right)$ of 0.8 throughout abdominal surgery to reduce the risk of surgical site infection. However, this recommendation has been widely criticised by anaesthetists and evidence from other clinical contexts has suggested that giving a high concentration of oxygen might worsen patient outcomes. This retrospective multi-centre observational study aimed to ascertain intraoperative oxygen administration practice by anaesthetists across parts of the UK.

Methods: Patients undergoing general anaesthesia with an arterial catheter in situ across hospitals affiliated with two anaesthetic trainee audit networks (PLAN, SPARC) were eligible for inclusion unless undergoing cardiopulmonary bypass. Demographic and intraoperative oxygenation data, haemoglobin saturation and positive end-expiratory pressure were retrieved from anaesthetic charts and arterial blood gases (ABGs) over five consecutive weekdays in April and May 2017.

Results: Three hundred seventy-eight patients from 29 hospitals were included. Median age was 66 years, 205 (54.2\%) were male and median ASA grade was 3. One hundred eight (28.6\%) were emergency cases. An anticipated difficult airway or raised BMI was documented preoperatively in $31(8.2 \%)$ and $45(11.9 \%)$ respectively. Respiratory or cardiac comorbidity was documented in 103 (27\%) and 83 (22\%) respectively. $\mathrm{SpO}_{2}<96 \%$ was documented in 83 (22\%) patients, with 7 (1.9\%) patients desaturating $<88 \%$ at any point intraoperatively. The intraoperative $\mathrm{FlO}_{2}$ ranged from 0.25 to 1.0, and median $\mathrm{PaO}_{2} / \mathrm{FlO}_{2}$ ratios for the first four arterial blood gases taken in each case were 24.6/0.5, 23.4/0.49, 25.7/0.46 and $25.4 / 0.47$ respectively.

Conclusions: Intraoperative oxygenation currently varies widely. An intraoperative $\mathrm{FIO}_{2}$ of 0.5 currently represents standard intraoperative practice in the UK, with surgical patients often experiencing moderate levels of hyperoxaemia. This differs from both WHO's recommendation of using an $\mathrm{FIO}_{2}$ of 0.8 intraoperatively, and also, the value most previous interventional oxygen therapy trials have used to represent standard care (typically $\mathrm{FIO}_{2}=0.3$ ). These findings should be used to aid the design of future intraoperative oxygen studies.
\end{abstract}

Keywords: Hyperoxia, Oxygen, Surgical procedures, Operative

\footnotetext{
* Correspondence: daniel.martin@ucl.ac.uk

${ }^{\dagger}$ Clare M. Morkane, Helen McKenna and Andrew F. Cumpstey contributed equally to this work.

${ }^{1}$ Division of Surgery and Interventional Science (University College London) and Royal Free Perioperative Research Group, Department of Anaesthesia,

Royal Free Hospital, 3rd Floor, Pond Street, London NW3 2QG, UK

Full list of author information is available at the end of the article
}

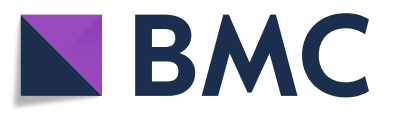

(c) The Author(s). 2018 Open Access This article is distributed under the terms of the Creative Commons Attribution 4.0 International License (http://creativecommons.org/licenses/by/4.0/), which permits unrestricted use, distribution, and reproduction in any medium, provided you give appropriate credit to the original author(s) and the source, provide a link to the Creative Commons license, and indicate if changes were made. The Creative Commons Public Domain Dedication waiver (http://creativecommons.org/publicdomain/zero/1.0/) applies to the data made available in this article, unless otherwise stated. 


\section{Background}

Approximately 3 million patients undergo general anaesthesia in the UK each year and are routinely given supplemental oxygen as part of this procedure (Sury et al. 2014). This makes oxygen one of the most commonly used drugs during surgery, yet there still remains considerable uncertainty about how much oxygen patients should receive during the perioperative period. In November 2016, the World Health Organization (WHO) recommended that all intubated patients receive a fractional inspired oxygen concentration $\left(\mathrm{FIO}_{2}\right)$ of 0.8 throughout surgery and for up to $6 \mathrm{~h}$ in recovery, as this might reduce patients' risk of developing a surgical site infection (SSI) later (Allegranzi et al. 2016). However, this recommendation has already been widely criticised by anaesthetists (Ball et al. 2017; Myles and Kurz 2017), and a Cochrane systematic review and meta-analysis of 28 trials published in 2015 concluded that robust evidence is lacking for a beneficial effect of using a high $\mathrm{FIO}_{2}$ to reduce SSIs (Wetterslev et al. 2015). In fact, this meta-analysis suggested using a high $\mathrm{FIO}_{2}$ during surgery could increase the risk of adverse events, including mortality, after long-term findings of the PROXI study (the largest study included in this review) reported significantly higher 2-year mortality rate in patients with abdominal malignancy who received an $\mathrm{FIO}_{2}$ of 0.8 (Wetterslev et al. 2015; Meyhoff et al. 2012).

WHO's recommendations would also appear to contradict the consensus opinion in other clinical contexts; concerns have been raised about potential harms associated with hyperoxaemia (defined by others as an arterial oxygen partial pressure $\left(\mathrm{PaO}_{2}\right)>13.3 \mathrm{kPa}$ or $100 \mathrm{mmHg}$ (Damiani et al. 2014a)) after myocardial infarction, after cardiac arrest and also in critical illness (Farquhar et al. 2009; Damiani et al. Dell'Anna et al. 2014). Within 15-30 min of onset, $\mathrm{FiO}_{2}$ 0.8-1.0 has also been demonstrated to induce atelectasis (Edmark et al. 2003), systemic vasoconstriction (Reinhart et al. 1991), coronary vasoconstriction (McNulty et al. 2005) and (within hours) pulmonary inflammation as well (Davis et al. 1983). Furthermore, chemical free radicals generated from oxygen (known as reactive oxygen species, ROS) can also avidly oxidise proteins, lipids or DNA resulting in cellular oxidative stress-an integral part of the normal surgical stress response that may also be associated with the development of multiple post-operative complications (Kücükakin et al. 2009). A large meta-analysis of over 16,000 patients concluded that high-quality evidence now shows liberal oxygen therapy in acutely ill adults increases mortality without improving other patient-important outcomes, suggesting that supplemental oxygen administration might become unfavourable above an $\mathrm{SpO}_{2}$ range of 94-98\% (Chu et al. 2018).

Currently, there is limited data describing the intraoperative oxygen administration practices of UK anaesthetists. Given the current controversy surrounding WHO's recommendations for perioperative oxygen use, the aim of this multi-centre observational study was to characterise practice as regards the administration of oxygen to patients undergoing major surgery and to describe intraoperative arterial oxygenation during general anaesthesia.

\section{Methods}

A multi-centre retrospective observational study was conducted across 29 hospitals in London and parts of the South Coast of England affiliated with two trainee-led research networks: PLAN (Pan-London Perioperative Audit and Research Network-http://www.uk-plan.net) or SPARC (South Coast Perioperative Audit and Research Collaborative-http://wessex-sparc.com). The project was confirmed to be a clinical service evaluation by the Royal Free London and Southampton NHS Trust Clinical Governance departments, and research ethics committee approval and individual patient consent were not required. Appropriate approval was secured from the clinical governance department in each participating hospital.

Patients aged 18 years and over undergoing general anaesthesia for elective or emergency operations necessitating the insertion of an arterial cannula and subsequent arterial blood gas (ABG) monitoring were included. Patients receiving cardiopulmonary bypass were excluded (as during bypass, oxygen administration is often not controlled by the anaesthetist).

Data collection took place over five consecutive weekdays in April and May 2017; flexibility in the data collection window ensured maximum compliance locally. Anaesthetic trainees not involved in the clinical care of the patients collected data from the anaesthetic record. Patients were identified and assessed for inclusion daily from departmental operating lists. A retrospective review of anaesthetic charts and arterial blood gases was performed after the patients in question had been moved from theatre to the recovery area, ward or intensive care unit. Oxygenation data (including intraoperative $\mathrm{SpO}_{2}, \mathrm{FIO}_{2}$ and $\mathrm{PaO}_{2}$ values), together with intraoperative positive end-expiratory pressure (PEEP) values and patient demographics, were collected using paper case report forms, held securely and treated as strictly confidential according to NHS policies.

Statistics were calculated using IBM SPSS Statistics, Version 24.0, Armonk, NY: IBM Corp. Data were examined for normality using the Shapiro-Wilk test. Unpaired data were compared using the Wilcoxon-Mann-Whitney $U$ test and Kruskal-Wallis tests. Correlation was tested with Spearman's rank correlation coefficient. All tests were two-tailed, and significance was taken as $p<0.05$. Continuous data were presented as median (IQR) and categorical data as number (percentage). Cumulative oxygen dose was determined in patients for whom more than one ABG was recorded, by calculating the area 
under the curve between the times of the first and final ABGs, in a plot of recorded $\mathrm{PaO}_{2}$ as a function of time, with T0 equal to the time of the initial ABG.

\section{Results}

Data from 378 anaesthetic cases were contributed from 29 hospitals across London and Wessex. Results were reported from 17 (58.6\%) district general hospitals (DGHs), $8(27.6 \%)$ teaching hospitals and $4(13.8 \%)$ speciality hospitals. Paper-based anaesthetic records were used in 334 (88.4\%) cases, with electronic records contributed by three sites. The median patient age was 66 years
(IQR 52-74). Patient demographics and clinical details along with operation characteristics are shown in Table 1.

Surgical duration ranged from 1 to $13 \mathrm{~h}$ with a median of $4 \mathrm{~h}$. Estimated blood loss was > $1000 \mathrm{ml}$ in 31 (8.2\%) patients. In total, 824 arterial blood gases were analysed. The number of ABGs recorded for each patient ranged from 1 to 13 , with a median of $2 . \mathrm{SpO}_{2}$ of $<96 \%$ was documented in 83 (22\%) patients, with only 7 (1.9\%) patients desaturating to $<88 \%$ at any point during the operation. Table 2 illustrates values for $\mathrm{SpO}_{2}, \mathrm{PaO}_{2}$ and haemoglobin concentration in the first five ABGs for each patient.

Table 1 Patient and operation characteristics

\begin{tabular}{|c|c|c|}
\hline Variable & & Patient/surgical characteristics number (\%) \\
\hline \multirow[t]{2}{*}{ Gender } & Male & 205 (54.2\%) \\
\hline & Female & $173(45.8 \%)$ \\
\hline \multirow[t]{6}{*}{ ASA classification } & 1 & $17(4.5 \%)$ \\
\hline & 2 & $158(41.8 \%)$ \\
\hline & 3 & $153(40.5 \%)$ \\
\hline & 4 & 34 (8.99\%) \\
\hline & 5 & $5(1.3 \%)$ \\
\hline & Not recorded & $11(2.9 \%)$ \\
\hline \multirow[t]{4}{*}{ Documented respiratory disease } & Asthma & $37(9.8 \%)$ \\
\hline & COPD & 31 (8.2\%) \\
\hline & Obstructive sleep apnoea & $10(2.6 \%)$ \\
\hline & Other & $25(6.6 \%)$ \\
\hline \multirow[t]{6}{*}{ Documented cardiovascular disease } & Hypertension & $145(38.4 \%)$ \\
\hline & Ischaemic heart disease & $49(13 \%)$ \\
\hline & Atrial fibrillation & $31(8.2 \%)$ \\
\hline & Congestive cardiac failure & $16(4.2 \%)$ \\
\hline & Valvular disease & $18(4.8 \%)$ \\
\hline & Other & $34(9 \%)$ \\
\hline \multirow{2}{*}{$\begin{array}{l}\text { National Confidential Enquiry into Patient } \\
\text { Outcome and Death (NCEPOD) classification }\end{array}$} & Elective & $270(71.4 \%)$ \\
\hline & Urgent/immediate/expedited & $108(28.6 \%)$ \\
\hline \multirow[t]{11}{*}{ Surgical specialty } & Upper gastrointestinal/colorectal/general/breast & $111(29.4 \%)$ \\
\hline & Urology/renal (including renal transplantation) & $34(9 \%)$ \\
\hline & Vascular & $37(9.8 \%)$ \\
\hline & Orthopaedics/spinal & $29(7.7 \%)$ \\
\hline & $\begin{array}{l}\text { Hepatopancreaticobiliary/liver transplant } \\
\text { (including liver transplantation) }\end{array}$ & $32(8.5 \%)$ \\
\hline & Ear nose and throat/maxillofacial & $17(4.5 \%)$ \\
\hline & Neurosurgery & $45(11.9 \%)$ \\
\hline & Gynaecology & $23(6.1 \%)$ \\
\hline & Cardiothoracic & $23(6.1 \%)$ \\
\hline & Plastics & $2(0.5 \%)$ \\
\hline & Other & $25(6.6 \%)$ \\
\hline
\end{tabular}


Table 2 Oxygenation and haemoglobin values from the first five sequential arterial blood gas samples

\begin{tabular}{lllll}
\hline $\mathrm{ABG}$ number & Median $\mathrm{FlO}_{2}(\mathrm{IQR})$ & ${\text { Median } \mathrm{PaO}_{2} \text { in } \mathrm{kPa}(\mathrm{IQR})}$ & Median P:F ratio in kPa (IQR) & Median haemoglobin concentration g/l (IQR) \\
\hline $1(n=378)$ & $0.5(0.45-0.59)$ & $24.5(16.7-32.6)$ & $51.2(36.9-66.0)$ & $113(100-126)$ \\
$2(n=227)$ & $0.49(0.4-0.54)$ & $23.4(17.4-29.5)$ & $50.6(38.1-62.9)$ & $111(100-124)$ \\
$3(n=116)$ & $0.46(0.4-0.51)$ & $25.7(19.6-29.2)$ & $54.5(43.3-65.2)$ & $108(99-119)$ \\
$4(n=51)$ & $0.47(0.4-0.5)$ & $25.4(20.7-30.8)$ & $57.2(43.9-71.1)$ & $111(93-153)$ \\
$5(n=24)$ & $0.49(0.3-0.51)$ & $26.3(23.4-29.3)$ & $58.6(45.3-66.7)$ & $99(93-116)$ \\
\hline
\end{tabular}

The median $\mathrm{PaO}_{2}$ and $\mathrm{FIO}_{2}$ for all analysed ABGs combined were $24.7 \mathrm{kPa}$ (IQR 17.9-30.8) and $0.50 \mathrm{kPa}$ (IQR 0.41-0.55) respectively. There was no significant difference in the $\mathrm{PaO}_{2}$ recorded across sequential ABGs $(p=0.23)$. Median $\mathrm{FIO}_{2}$ was also consistent across sequential ABGs, although the variation about the median decreased by the fifth ABG (Fig. 1). Figure 1b demonstrates marked spread of data and a weak positive

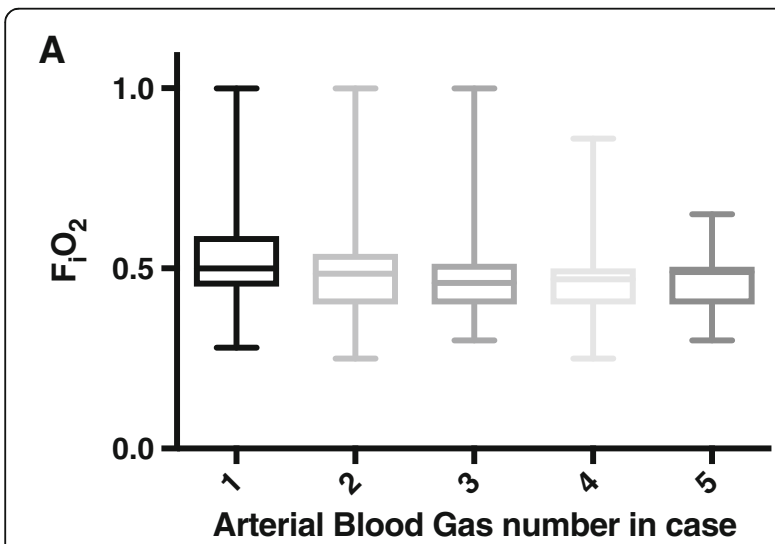

B

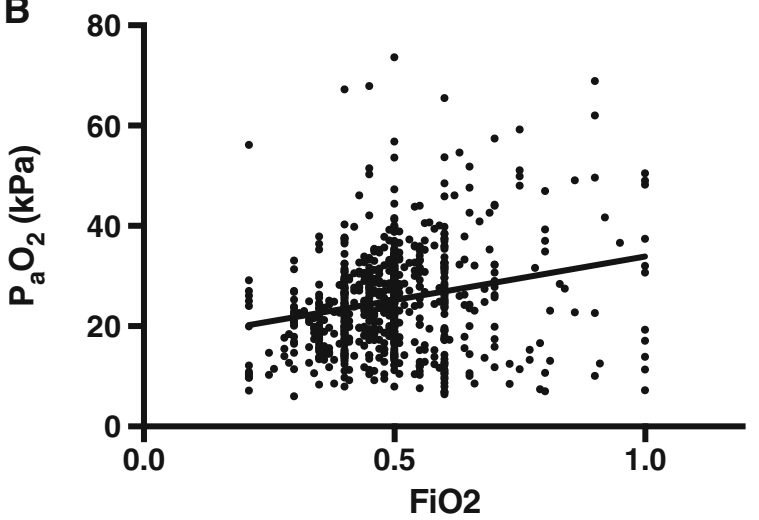

Fig. 1 Intraoperative oxygenation illustrated by a box and whisker plot illustrating $\mathrm{FIO}_{2}$ administered over first five $A B G s$. Boxes are drawn between 25th and 75th percentiles with the median represented by a line and the whiskers indicating the minimum and maximum values. b Scatter plot and linear relationship between $\mathrm{FIO}_{2}$ and $\mathrm{PaO}_{2}$ for each $\mathrm{ABG}$. The continuous line represents the relationship between partial pressure of arterial oxygen recorded and the fraction of inspired oxygen delivered $(r=0.22, p \leq 0.001)$ association between measured $\mathrm{PaO}_{2}$ and $\mathrm{FIO}_{2}(r=0.22$, $p \leq 0.001$ ). Supraphysiological values for $\mathrm{PaO}_{2}$ (defined as $>13.3 \mathrm{kPa})$ were observed in $734(89 \%)$ ABGs. Of the 769 ABGs for which the corresponding $\mathrm{FIO}_{2}$ was recorded, an $\mathrm{FIO}_{2} \geq 0.8$ was administered on 32 (4.2\%) occasions. Of these 32 occasions, $20(62.5 \%)$ were at the time of taking the baseline arterial gas, closest to induction of anaesthesia.

The median cumulative oxygen dose, calculated for those patients for whom at least two ABGs were documented $(n=223)$, was $3824 \mathrm{kPa}$ min (IQR 2121-6923) over a median time of $159 \mathrm{~min}$ (IQR 91-291). The administration of $13.3 \mathrm{kPa} \mathrm{O} \mathrm{O}_{2}$ over the same time period would have resulted in a median cumulative oxygen dose of $2088 \mathrm{kPa}$. Representative traces of the cumulative oxygen dose administered to four individual patients are illustrated in Fig. 2.

Positive end-expiratory pressure (PEEP) was recorded in 287 (75.9\%) of cases, and the median PEEP administered was $5 \mathrm{cmH}_{2} \mathrm{O}$ (range 0-12). A PEEP of 4,5 or $6 \mathrm{cmH}_{2} \mathrm{O}$ was administered in 207 (72.1\%) of cases where PEEP was recorded. A change in the level of PEEP administered was documented during only 28 cases.

\section{Discussion}

These results demonstrate that the amount of oxygen anaesthetists administer to adult patients undergoing major surgery in the UK currently varies widely-the recorded $\mathrm{FIO}_{2}$ ranged from 0.25 to 1.0 throughout surgery. In many patients, $\mathrm{FIO}_{2}$ was nearer 0.5 for the duration of surgery, resulting in $\mathrm{PaO}_{2}$ values of approximately $25 \mathrm{kPa}$ throughout.

An $\mathrm{FIO}_{2}$ of 0.5 is much higher than "standard" therapy used for control groups (where $\mathrm{FIO}_{2}$ is typically 0.3) in previous studies of "high" versus "standard" oxygen therapy (Wetterslev et al. 2015) and also considerably less than the WHO now recommends (Allegranzi et al. 2016). Interestingly, the findings from this UK-based sample exactly match values recently reported as representing current practice in the Cleveland Clinic, USA (Kurz et al. 2018). These results are also similar to the LAS VEGAS study (a prospective cross-sectional study of 9808 patients from 29 different countries) where half of all patients received an $\mathrm{FIO}_{2}$ between 0.4 and 0.6 and one third between 0.6 and 

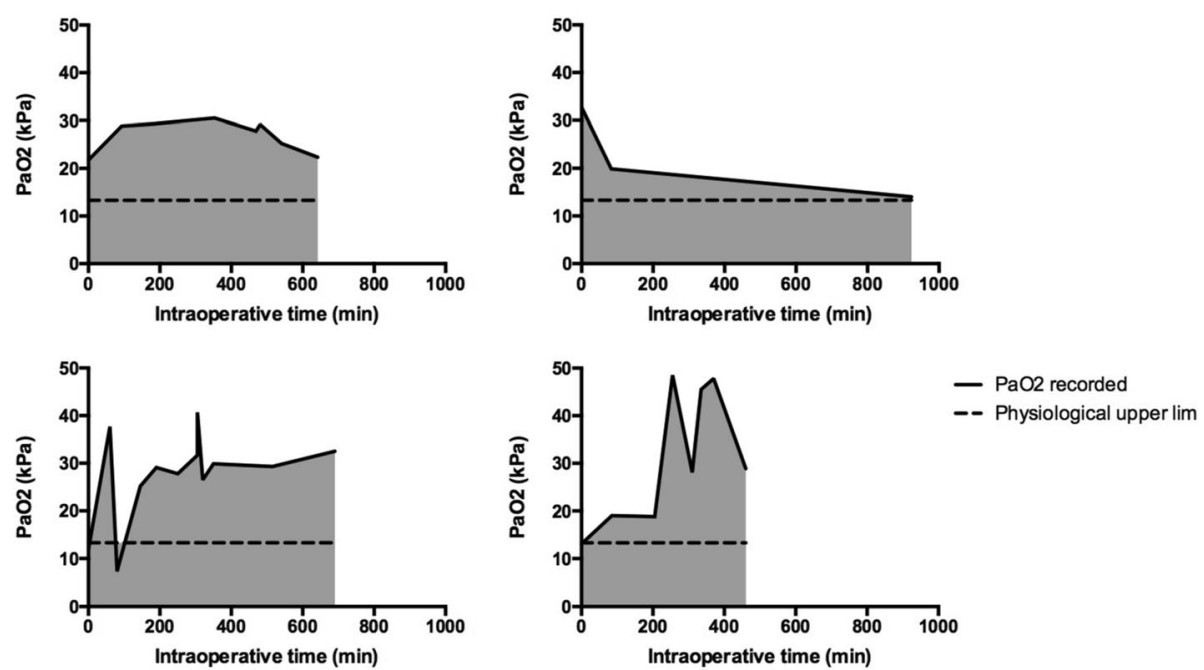

Fig. 2 Sample traces demonstrating of cumulative oxygen dose for four individual patients. The solid line represents the actual $\mathrm{PaO}_{2}$ recorded in successive blood gases, whilst the dashed line represents the physiological upper limit (13.3 kPa). Area under the curve (shaded) was calculated between the times of the first and final $A B G s$

0.8 Rogerson et al. (2017). LAS VEGAS also reported a median PEEP of $5 \mathrm{cmH}_{2} \mathrm{O}$ (the value in $>50 \%$ cases where PEEP was recorded in this study) suggesting this also represents the current "standard" of practice Rogerson et al. (2017).

In many other clinical contexts, including on the critical care unit, $\mathrm{PaO}_{2}$ values around $25 \mathrm{kPa}$ would likely be classed as moderate hyperoxia rather than normoxia (Damiani et al. 2014a). However, median intraoperative $\mathrm{PaO}_{2}$ values of approximately $25 \mathrm{kPa}$ are consistent with an earlier single UK centre pilot study carried out by our group, reporting a mean $\mathrm{PaO}_{2}$ of $24.4 \mathrm{kPa}$ in 75 surgical patients over a 6-week period (Martin and Grocott 2015), and observational data also suggests that current practice still favours hyperoxaemia in critically ill patients (de Jonge et al. 2008; Eastwood et al. 2012).

Intraoperative hyperoxaemia may be a consequence of several factors. Firstly, up to now, evidence associating hyperoxia under anaesthesia with harm has been relatively limited. However, high intraoperative $\mathrm{FIO}_{2}$ has been retrospectively associated in a dose-dependent manner with increased post-operative respiratory complications and with increased mortality (Staehr-Rye et al. 2017); the PROXI study demonstrated a higher 2-year mortality in patients with abdominal malignancy who received an $\mathrm{FIO}_{2}$ of 0.8 ; and similarly, in 2018, a trial of over 5000 patients reported that using an $\mathrm{FIO}_{2}$ of 0.8 intraoperatively instead of 0.3 did not alter SSI rates but did double 30-day mortality rates $(p=0.08)$ (Kurz et al. 2018). Secondly, continuous monitoring of arterial oxygenation during general anaesthesia occurs mainly via pulse oximetry with a scale that stops at $100 \%$. New technology may allow non-invasive measurement of surrogate markers of $\mathrm{PaO}_{2}$ in the future (e.g. the oxygen reserve index (Applegate et al. 2016)), but the use of these devices is currently limited. The duration of oxygen exposure may also possibly affect the outcomes, yet this has often not been considered or reported in clinical trials previously. The method of determining cumulative oxygen dose demonstrated here could represent a more relevant measure for use in future outcome studies.

\section{Strengths and limitations}

This study characterises how anaesthetists in the UK currently use oxygen during a mixed selection of major surgery and in a large number of different hospitals. The biggest limitation to these findings is that corresponding clinical outcomes could not be collected. This should be a focus of future prospective research studies, and although this study was never designed to collect outcome data itself, our findings that $\mathrm{FIO}_{2}$ of 0.5 currently represents "standard care" (and not 0.3 as used by most trials to date) should be considered in the design of future trials. Area under the curve analysis could only be performed between times of arterial blood gas sampling, which could not be specified due to the retrospective and observational study design, and consequently, our data may represent underestimates of total cumulative oxygen doses as $\mathrm{FIO}_{2}$ is often increased at the start and end of anaesthesia to prepare for intubation and extubation. Because of the way most recruiting hospitals routinely document anaesthesia, the majority of data were collected from paper anaesthetic records. Previous studies have suggested a paper anaesthetic chart is not always the most accurate record of 
intraoperative events (Devitt et al. 1999); however, in our study, findings from centres using paper charts were still very similar to those using electronic recording systems. In order to record $\mathrm{PaO}_{2}$ values, we included patients undergoing procedures necessitating arterial line insertion; implying our findings might only be applicable to those in whom invasive monitoring was deemed necessary by the anaesthetist, either due to patient or operative factors. However, despite all of these limitations, our findings corroborated reports of current practice in other countries exactly (Kurz et al. 2018).

\section{Conclusions}

Anaesthetists are currently faced with an international recommendation on the intraoperative administration of oxygen that conflicts with the majority of evidence from other clinical contexts. It is perhaps not surprising therefore that the amount of oxygen administered to patients undergoing general anaesthesia in the UK varies widely. The administration of an $\mathrm{FIO}_{2}$ of 0.5 appears to be the current standard of care for UK-based anaesthetists, which is often associated with moderate levels of hyperoxaemia intraoperatively. These findings are very similar to the reports from other countries and need to be considered in the design of any future studies investigating the potential impact intraoperative oxygen therapy may have on surgical patients' outcomes.

\section{Abbreviations \\ ABG: Arterial blood gas; DGH: District general hospital; $\mathrm{F}_{1} \mathrm{O}_{2}$ : Fractional inspired oxygen concentration; IQR: Interquartile range; $\mathrm{PaO}_{2}$ : Arterial oxygen partial pressure; PEEP: Positive end-expiratory pressure; PLAN: Pan-London Perioperative Audit and Research Network; ROS: Reactive oxygen species; SPARC: South Coast Perioperative Audit and Research Collaborative; $\mathrm{SpO}_{2}$ : Peripheral oxygen saturation; SSI: Surgical site infection; WHO: World Health Organization}

\footnotetext{
Acknowledgements

PLAN:

Louise Carter, Cyrus Razavi, Ryan Howle, Alex Eeles, Kate C. Tatham, Victoria Winter, Lena Al-Shammari, Leda Lignos, Gagandeep Dhotar, Emma Karsten, Justine Lowe, Noel Young, Lindsey lles, Colin Coulter, Michael Shaw, Liam Gleeson, Liana Zucco, Charlie Cox, Amanda Bruce, John N Cronin, James Arlidge, Rachel Krol, Rasha Abouelmagd, Phil Dart, Mohamed Ahmed, Kathy Shammas, Carly Webb, Luke Foster, Rafi Kanji, Darragh Hodnett, Lusha Suntharanathan, Amy Sangam, Zain Malik, Eleanor Jeffreys, Jonathan Williamson, Marika Chandler, Nick Dennison, Jan Schumacher, Kariem El-Boghdadly, Peter Odor, Helen Laycock, Sibtain Anwar, Harriet Wordsworth, Alex Wickham, Shaima Elnour, Edward Burdett, Sioned Phillips, Matt Oliver, Carolyn Johnston, Mitul Patel, Kate Grailey, Queenie Lo, Benjamin Frost, James O'Carroll, Hew D Torrance, Vimal Grover, Chris Whiten, Justine Lowe, Matthew C. Dickinson, Vanessa Cowie, Richard George, Julian Giles, Otto Mohr, Ahmer Mosharaf, Jon Brammall. SPARC:

Jamie Plumb, Alexander I. R. Jackson, Erica Jolly, Huw Wilkins, Hannah Wong, Suzanne Shuttleworth, Nick Hayward, J. Joseph Kinsella, Emma Killick, Tom Daubeny, Philip McGlone, Sophie Yelland, Kushmandinie Goonetilleke, Victoria Tuckey, Alan Radford, Rebecca Fry, Jessie Rose, Mukunder Patel, Hugh Cutler, Kate Blethyn, Jeremy Whittles, Paul Stevens, Rebecca Sands, Matt Taylor, Fiona Linton, Tom Blincoe, Lucy Chumas, Sarah Bates, Heidi Lightfoot, Olivia Shields, Francesca Riccio.
}

\section{Availability of data and material}

The datasets used and/or analysed during the current study are available from the corresponding author on reasonable request.

\section{Authors' contributions}

CMM, HM and AFC contributed to the study conception and design, data collection, data analysis and writing of the manuscript. AO contributed to the study design and data collection. DSM and MPWG contributed to the study conception and design and writing and editing of the manuscript. All authors read and approved the final manuscript.

\section{Ethics approval and consent to participate}

Research and development departments at both the Royal Free Hospital and University Hospital Southampton reviewed the study separately and agreed that as the study was a service evaluation, research ethics approval was not required. Local governance approval was obtained at every participating centre.

\section{Consent for publication}

Not applicable.

\section{Competing interests}

Professor Michael P. W. Grocott (MPWG) serves on the medical advisory board of Sphere Medical Ltd. and is a director of Oxygen Control Systems $L t d$. He has received honoraria for speaking for and/or travel expenses from BOC Medical (Linde Group), Edwards Lifesciences and Cortex GmBH. MPWG leads the Xtreme Everest Oxygen Research Consortium and the Fit-4-Surgery research collaboration. Some of this work was undertaken at University Southampton NHS Foundation Trust-University of Southampton NIHR Biomedical Research Centre. MPWG serves as the UK NIHR CRN national specialty group lead for Anaesthesia Perioperative Medicine and Pain and is an elected council member of the Royal College of Anaesthetists, an elected board member of the Faculty of Intensive Care Medicine and president of the Critical Care Medicine Section of the Royal Society of Medicine. Daniel Martin has received consultancy fees from Siemens Healthcare and Masimo and lecture honoraria from Edwards Lifesciences and Deltex Medical. He is also a Director of Oxygen Control Ltd.

Dr. Andrew Cumpstey is currently funded through the NIHR as an Academic Clinical Fellow. The other authors declare that they have no competing interests.

\section{Publisher's Note}

Springer Nature remains neutral with regard to jurisdictional claims in published maps and institutional affiliations.

\section{Author details}

${ }^{1}$ Division of Surgery and Interventional Science (University College London) and Royal Free Perioperative Research Group, Department of Anaesthesia, Royal Free Hospital, 3rd Floor, Pond Street, London NW3 2QG, UK. ²University of Southampton/University Hospital Southampton and NIHR Biomedical Research Centre, Tremona Rd, Southampton SO16 6YD, UK. ${ }^{3}$ University Hospital Southampton, Tremona Rd, Southampton SO16 6YD, UK.

Received: 4 May 2018 Accepted: 6 July 2018

Published online: 24 July 2018

\section{References}

Allegranzi B, Zayed B, Bischoff P, Kubilay NZ, de JS, de VF, et al. New WHO recommendations on intraoperative and postoperative measures for surgical site infection prevention: an evidence-based global perspective. Lancet Infect Dis. 2016;16(12):e288-303.

Applegate RL, Dorotta IL, Wells B, Juma D, Applegate PM. The relationship between oxygen reserve index and arterial partial pressure of oxygen during surgery. Anesth Analg. 2016;123(3):626-33.

Ball L, Lumb AB, Pelosi P. Intraoperative fraction of inspired oxygen: bringing back the focus on patient outcome. BJA Br J Anaesth. 2017;119(1):16-8.

Chu DK, Kim LH-Y, Young PJ, Zamiri N, Almenawer SA, Jaeschke R, et al. Mortality and morbidity in acutely ill adults treated with liberal versus conservative oxygen therapy (IOTA): a systematic review and meta-analysis. Lancet. 2018; 391(10131):1693-705 
Damiani E, Adrario E, Girardis M, Romano R, Pelaia P, Singer M, et al. Arterial hyperoxia and mortality in critically ill patients: a systematic review and meta-analysis. Crit Care. 2014;18(16):711.

Davis WB, Rennard SI, Bitterman PB, Crystal RG. Pulmonary oxygen toxicity. N Engl J Med. 1983;309(15):878-83.

de Jonge E, Peelen L, Keijzers PJ, Joore H, de Lange $\mathrm{D}$, van der Voort PH, et al. Association between administered oxygen, arterial partial oxygen pressure and mortality in mechanically ventilated intensive care unit patients. Crit Care. 2008;12(6):R156.

Dell'Anna AM, Lamanna I, Vincent J-L, Taccone FS. How much oxygen in adult cardiac arrest? Crit Care. 2014;18:555.

Devitt JH, Rapanos T, Kurrek M, Cohen MM, Shaw M. The anesthetic record: accuracy and completeness. Can J Anaesth J Can Anesth. 1999;46(2):122-8.

Eastwood G, Bellomo R, Bailey M, Taori G, Pilcher D, Young P, et al. Arterial oxygen tension and mortality in mechanically ventilated patients. Intensive Care Med. 2012;38(1):91-8.

Edmark L, Kostova-Aherdan K, Enlund M, Hedenstierna G. Optimal oxygen concentration during induction of general anesthesia. Anesthesiol J Am Soc Anesthesiol. 2003;98(1):28-33.

Farquhar H, Weatherall M, Wijesinghe M, Perrin K, Ranchord A, Simmonds M, et al. Systematic review of studies of the effect of hyperoxia on coronary blood flow. Am Heart J. 2009:158(3):371-7.

Kücükakin B, Gögenur I, Reiter RJ, Rosenberg J. Oxidative stress in relation to surgery: is there a role for the antioxidant melatonin? I Surg Res. 2009;152(2): $338-47$.

Kurz A, Kopyeva T, Suliman I, Podolyak A, You J, Lewis B, et al. Supplemental oxygen and surgical-site infections: an alternating intervention controlled trial. Br J Anaesth. 2018;120(1):117-26.

Martin DS, Grocott MPW. Oxygen therapy and anaesthesia: too much of a good thing? Anaesthesia. 2015;70(5):522-7.

McNulty PH, King N, Scott S, Hartman G, McCann J, Kozak M, et al. Effects of supplemental oxygen administration on coronary blood flow in patients undergoing cardiac catheterization. Am J Physiol - Heart Circ Physiol. 2005; 288(3):H1057-62

Meyhoff CS, Jorgensen LN, Wetterslev J, Christensen KB, Rasmussen LS, PROX Trial Group. Increased long-term mortality after a high perioperative inspiratory oxygen fraction during abdominal surgery: follow-up of a randomized clinical trial. Anesth Analg 2012;115(4):849-854.

Myles PS, Kurz A. Supplemental oxygen and surgical site infection: getting to the truth. BJA Br J Anaesth. 2017;119(1):13-5.

Reinhart K, Bloos F, König F, Bredle D, Hannemann L. Reversible decrease of oxygen consumption by hyperoxia. Chest. 1991;99(3):690-4.

Rogerson D, Williams JP, Yates S, Rogers E. Epidemiology, practice of ventilation and outcome for patients at increased risk of postoperative pulmonary complications. Eur J Anaesthesiol. 2017;34(8):492-507.

Staehr-Rye AK, Meyhoff CS, Scheffenbichler FT, MF MV, Gätke MR, et al. High intraoperative inspiratory oxygen fraction and risk of major respiratory complications. BJA Br J Anaesth. 2017:119(1):140-9.

Sury MRJ, Palmer JHMG, Cook TM, Pandit JJ, Mahajan RP. The state of UK anaesthesia: a survey of National Health Service activity in 2013. BJA Br J Anaesth. 2014;113(4):575-84.

Wetterslev J, Meyhoff CS, Jørgensen LN, Gluud C, Lindschou J, Rasmussen LS. The effects of high perioperative inspiratory oxygen fraction for adult surgical patients. Cochrane Database Syst Rev. 2015;6(6). https://doi.org/10.1002/ 14651858.CD008884.pub2.

\section{Ready to submit your research? Choose BMC and benefit from:}

- fast, convenient online submission

- thorough peer review by experienced researchers in your field

- rapid publication on acceptance

- support for research data, including large and complex data types

- gold Open Access which fosters wider collaboration and increased citations

- maximum visibility for your research: over $100 \mathrm{M}$ website views per year

At BMC, research is always in progress.

Learn more biomedcentral.com/submissions 